\title{
Characterization of the urban heat island at Bucaramanga, Colombia, using real-fime temperature monitoring
}

\author{
Caracterización de la isla de calor urbana en Bucaramanga, Colombia, monitoreando \\ temperatura en tiempo real
}

\section{Hildreth Jadira Villamil-Almeida ${ }^{1}$, Kevin Andrés Blanco-Mantilla ${ }^{1}$, Oscar Yazit Salah-García (iD) ${ }^{2}$, Carlos Eduardo García-Sánchez (iD ${ }^{1,2 *}$}

${ }^{1}$ Escuela de Ingeniería Química, Universidad Industrial de Santander. Carrera 27 Calle 9. C.P. 680001 . Bucaramanga, Colombia.

${ }^{2}$ Corporación Centro de Desarrollo Tecnológico del Gas, Carrera 23 \# 106-08. C. P. 680004. Bucaramanga, Colombia.

\section{CITE THIS ARTICLE AS:}

H. J. Villamil, K. A. Blanco, 0.

Y. Salah and C. E. García.

"Characterization of the urban

heat island at Bucaramanga,

Colombia, using real-time

temperature monitoring",

Revista Facultad de Ingeniería

Universidad de Antioquia, no.

97, pp. 10-21, Oct-Dec 2020.

[Online]. Available: https:

//www.doi.org/10.17533/

udea.redin. 20191260

\section{ARTICLE INFO:}

Received: July 24, 2019

Accepted: December 20, 2019

Available online: December

20,2019

\section{KEYWORDS:}

Urban heat island;

Bucaramanga; real-time

monitoring; data processing

Isla de calor urbana;

Bucaramanga; monitoreo en tiempo real; procesamiento de datos

\begin{abstract}
One of the meteorological effects in cities is the increase in local temperature, which is known as urban heat island (UHI). The objective of this study was to detect and quantify the possible UHI in the city of Bucaramanga, Colombia. For this purpose, a real-time temperature measurement network was installed, composed of seven nodes, used to obtain temperature values every minute. Six of the nodes were located in different positions in the city, and the remaining one was used to give the reference measurement. The data collected were processed for elimination of outliers, management of missing data and noise filtering. Analysis of the data allowed detecting differences in the diurnal and nocturnal UHI intensity trends. It was concluded that the UHI intensity during the day varies depending on the Local Climate Zone that represents the location, while the UHI intensity value at night is quite uniform across the city, with a mean value of $1.0^{\circ} \mathrm{C}$. It was also possible to conclude that the magnitude of the daytime $\mathrm{UHI}$ is lower in the dry season.
\end{abstract}

RESUMEN: Uno de los efectos meteorológicos en las ciudades es el incremento de la temperatura local, lo que se conoce como isla de calor urbana (UHI, por sus siglas en inglés). El objetivo de este estudio fue detectar y cuantificar la posible UHI en Bucaramanga, Colombia. Para este fin, una red de medición de temperatura en tiempo real fue instalada, la cual estaba compuesta por siete nodos, con los que se obtenían valores de temperatura cada minuto. Seis de los nodos fueron ubicados en diferentes sitios de la ciudad, y el restante fue usado para dar la medición de referencia. Los datos recolectados fueron procesados para eliminar datos atípicos, administrar los datos faltantes y reducir el ruido. El análisis de los datos permitió detectar diferencias en las tendencias de la intensidad de las UHI diurna y nocturna. Se concluyó que la intensidad de la UHI durante el día varía dependiendo de la Zona de Clima Local que representa el sitio, mientras que el valor de la intensidad de la UHI de noche es bastante uniforme a través de la ciudad, con un valor promedio de $1,0^{\circ} \mathrm{C}$. También fue posible concluir que la magnitud de la UHI diurna es menor en la temporada seca.

\section{Introduction}

Nowadays, there is a growing interest in the urban climatology [1]. This is driven by the progressive increase in the proportion of human population living in cities and urban regions, going from $33 \%$ in 1960 to almost $55 \%$ in 2017 [2], and by the fact that human activities in cities cause

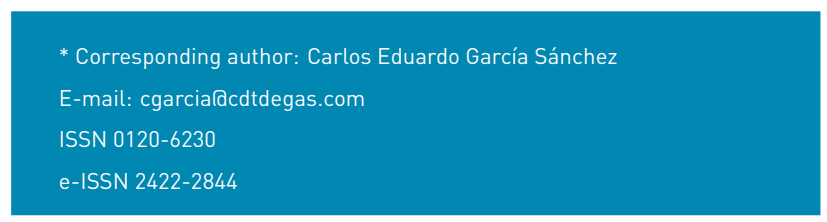

approximately $75 \%$ of the total energy consumption, although cities occupy only about $2 \%$ of the earth's surface [3]. One of the most prominent aspects of urban climatology is urban heat island (UHI), which is the region that has a higher temperature due to the presence of an urban zone [4]. Observations of UHI started in the nineteenth century, although some authors consider that modern UHI studies, along with urban climatology, began with Sundborg's 1951 study of the city of Uppsala, Sweden [5]. Despite this, there are multiple UHI intensity definitions in use, including air temperature difference 
between an urban area and its rural surroundings le.g. [6-9]], difference of air temperature in a city respect to air temperature outside of the city at the same altitude [10], difference between the air temperature in a city and the temperature that would be measured without the city [11], difference between surface temperature of urban area and suburban area [12], temperature difference spatially averaged between an urban area and one or several rural areas that surround it [13], maximum temperature difference measured between urban and rural sites [14], and temperature difference between urban and rural sites under stable weather conditions [15]. Therefore, the reported value of the UHI depends not only on the properties of the evaluated city, but also on the chosen UHI definition and the characteristics of the place used as reference [4]. Publications about UHI have been increasing during the past three decades [16]. Several impacts have been attributed to UHI, among which are magnification of heat waves [17], effects on water and energy consumption [18], increase of pollutants and greenhouse gases emission, and effects on human health [19].

According to the vertical scale, there are three types of UHI: surface, canopy and boundary layer. Surface UHI refers to temperature difference between city surface materials and rural soils and plants $[4,12]$, which habitually is determined using satellite information and depends on seasonality, the ecosystems, the solar radiation and the cloud cover $[7,20]$. The UHI in the space between ground and roof level in the city is known as canopy UHI [21]. In this region, energy transfer are microscale processes which affects energy distribution, in conjunction with composition and geometry of the city landscape [1]. Urban boundary UHI manifests in the urban atmosphere above and downwind the city $[4,22]$. The most interesting type of UHI is the canopy UHI. Most of the papers in this topic are related with UHI determination, especially with UHI generation factors and environmental effects [16]. Air temperature measurement for determination of this kind of UHI must be measured with a thermometer exposed to the air but sheltered from solar radiation [23]. Although it is common to measure air temperature for meteorological applications at a height of $2 \mathrm{~m}[20,24]$, sometimes practical considerations have led to the use of higher heights in UHI studies (e.g. [14, 21, 24, 25]). There has not been a standard methodology for UHI studies, so some studies recollected data using automobiles which carried the thermometers [26-30], while others used fixed sensors, with different levels of representativeness: some used one urban and one rural $[9,11,15,21,31]$; others used multiple urban and one rural $[24,32]$; others used one urban and multiple rural $[33,34]$; and others used multiple urban and multiple rural $[14,17,25,28,35-38]$. There are also marked differences with respect to the length of the period of time used in the studies, ranging from some days $[6,24,26,27,29,34,37]$ to some years $[9,10,14,15,21,30]$, and even decades $[11,17,31,33,35,36,39]$. Besides temperature, some studies have used measurement of other variables such as humidity, wind speed, wind direction and cloud coverage (e.g. [15, 21, 26, 30, 32]). Another approach for UHI studies has been modeling and simulation. Working in this category has been diverse [40], including use of energy balance model, application of computational fluid dynamics [27], meso-scale model $[35,41]$, micro-scale model [22] and regression [30, 31, 39].

Two widespread problems in heat island literature are lack of appropriate control of confounding variables and insufficient information about site and characteristics of the measurements [42]. Despite this and the diversity of methodologies and approaches, there are some results that can be considered general [16]. UHI intensity tends to be higher at night $[9,10,13,21,30,32]$, and tends to decrease with increasing wind speed [22, 26, 31, 43]. Similarly, UHI presents a tendency of increase with city population [26, 28], although after a certain stage of city development it tends to stabilize $[10,11,33,36,44]$. In many cases, it has been reported that UHI intensity varies with season, with the particular stations used in the study, with latitude, and with the presence of constructions upstream of the city $[6,10,29,31,34,37,38,41,45-48]$.

The main causes of UHI are anthropogenic heat and pollutants emission, building configurations that create urban street canyons and decrease wind speed, and difference of properties between the building materials and the natural environment, including higher long wave radiation capture, lower permeability, lower albedo and lower capacity for water evaporation [4, 9, 21, 35, 49-51]. To deal with the thermal discomfort caused by UHI, it is possible to use adaptation or mitigation strategies. Adaptation actions include the use of passive cooling in buildings, increasing efficiency of cooling equipment, and adaptation in clothes and life style [52]. On the other hand, mitigation strategies have the objective of diminish the UHI intensity, and in this way they would decrease energetic consumption and pollutant levels, and improve the comfort of the inhabitants [43]. This kind of strategy can be based on decreasing the absorption of solar radiation, improving the flow of air through the city, cooling some elements of the built environment, or decreasing the anthropogenic heat [53]. Some mitigation actions must be incorporated in the planning strategy of the city, like reservation of green zones and its adequate distribution in the city, urban form, selection of built form and use of materials with favorable characteristics [3, 19,54-56]. Modeling can be a valuable tool in urban planning for UHI mitigation $[41,49,57]$, though the current models do not yet have the necessary predictive potential $[53,58]$. Other mitigation 
actions are increasing the number of planted trees, and use of cool roofs, green roofs, vertical gardens and cool pavements $[3,12,14,25,29,43,57,59]$. Integration of different techniques can be important to study the effect of UHI mitigating actions [40].

\subsection{Description of the case study}

The objective of this study was to quantify the UHI intensity in Bucaramanga, Colombia. It was decided to focus the study on Bucaramanga because there is no previous research about the UHI in this city. Additionally, there is a sub-representation of tropical and subtropical cities in the literature on urban climate, accounting for approximately $20 \%$ of the total number of studies in the topic [48]. This city is located in the northeastern region of Colombia, on a plateau in an edge of the Cordillera Oriental ("Eastern Mountain Range"), and has an altitude of 959 meters above sea level (MASL). It is bordered by mountains to the east, and by the canyon of the Río de Oro river to the west. In the Supplementary Material, Figure S1 shows the surroundings of the city. These surroundings limit the difference between daytime and nighttime temperatures, due to the flow of cool wind from the mountains during the day and warm wind at night from the canyon. This characteristic also confers a particular interest to the analysis of the magnitude of the UHI in Bucaramanga. Climate through the year can be classified in rainy season, which occurs between April and May and between September and November, and dry season the rest of the year. The climate of Bucaramanga can be categorized as tropical savanna in the Köppen-Geiger classification [60]. It is interesting to note that according to Colombian IDEAM data, Bucaramanga would have a tropical monsoon climate, but those data are taken at the Palonegro airport, which is $15 \mathrm{~km}$ from the city and has an altitude of 1188 MASL [61]. According to estimations of the Colombian Departamento Nacional de Estadística (DANE), Bucaramanga has a population of approximately 520,000, and its Metropolitan Area lcomposed of Bucaramanga and other three nearby cities: Floridablanca, Girón y Piedecuestal reaches a population of approximately 1.1 million [62].

\section{Materials and methods}

Seven small measurement stations were developed for this study. Those stations formed a measurement network, so that they will be called "nodes". Each node had two thermometers and communication capabilities over GSM cellular network, and its required electric power was provided by solar panels. Temperature was measured with digital thermometers Maxim Integrated DS18B20, whose sensing element uses the physical properties of transistors on the die, and according with the manufacturer have an accuracy of $0.5^{\circ} \mathrm{C}$. The use of two thermometers in each node allowed detecting the possible presence of measurement problems. The thermometers were located under the solar panel, sheltered from direct sunlight and rain. A special care was taken to avoid that the sensing region was in contact with other components of the node, to avoid bias in the measurement due to conductive heat transfer. Before starting the period of study, thermometers used in the nodes were calibrated in an ISO/IEC 17025 accredited laboratory. Figure 1 shows the dimensions of the nodes, without including the solar panel.

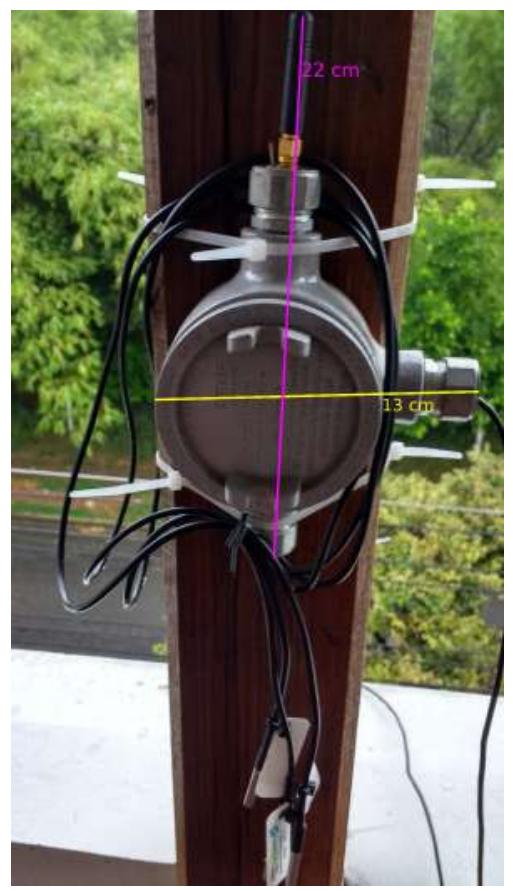

Figure 1 Node of the measurement network deployed in the study

Data acquisition and transmission were done using real-time sensors and wireless communication, and data were stored in a server. The use of real-time sensors and meters allows the registration of large volumes of data, which requires the use of specialized tools for collection, storage and processing, and sometimes also for interpretation, depending on the application [63]. In the present work, techniques were applied to raw data for outlier removal, missing data imputation, and noise filtering.

One of the nodes was used to provide the reference measurement, and the others reported temperature in different sites of the city. The reference node was installed on an edge of the city, at an undeveloped place which has the natural vegetation that occurs in the area where is built Bucaramanga. Thereby, the reference measurements obtained are the best possible approximation to the ideal 
Table 1 Code, location and local climates zones of the measurement nodes used in the study

\begin{tabular}{|c|c|c|c|c|c|c|c|}
\hline $\begin{array}{l}\text { Node } \\
\text { code }\end{array}$ & $\begin{array}{l}\text { Node } \\
\text { category }\end{array}$ & Coordinates & $\begin{array}{l}\text { Approximate } \\
\text { building } \\
\text { surface } \\
\text { fraction [\%] }\end{array}$ & $\begin{array}{l}\text { Approximate } \\
\text { impervious } \\
\text { surface } \\
\text { fraction [\%] }\end{array}$ & $\begin{array}{l}\text { Approximate } \\
\text { pervious } \\
\text { surface } \\
\text { fraction [\%] }\end{array}$ & $\begin{array}{l}\text { Mean } \\
\text { height of } \\
\text { roughness } \\
\text { elements }\end{array}$ & LCZ \\
\hline EQ-229 & Reference & $\begin{array}{l}7^{\circ} 07^{\circ} 07.06 " \mathrm{~N} \\
73^{\circ} 07^{\prime} 55.13^{\prime \prime} \mathrm{W} \\
\end{array}$ & 5 & 10 & 85 & $4 \mathrm{~m}$ & LCZ B \\
\hline EQ-230 & Urban & $\begin{array}{l}7^{\circ} 07^{\prime} 04.70^{\prime \prime} \mathrm{N} \\
7^{\circ} 07^{\prime} 34.10^{\prime \prime} \mathrm{W}\end{array}$ & 85 & 10 & Less than 5 & $\begin{array}{l}\text { Between } \\
4 \text { and } 5 \\
\text { stories }\end{array}$ & LCZ 2 \\
\hline EQ-231 & Urban & $\begin{array}{l}7^{\circ} 07^{\prime} 10.22 " \mathrm{~N} \\
7^{\circ} 07^{\prime} 19.41 " \mathrm{~W}\end{array}$ & 50 & 30 & 20 & $\begin{array}{l}\text { Between } \\
3 \text { and } 4 \\
\text { stories }\end{array}$ & LCZ 5 \\
\hline EQ-232 & Urban & $\begin{array}{l}7^{\circ} 06^{\prime} 51.67 " \mathrm{~N} \\
73^{\circ} 07^{\prime} 49.31 " \mathrm{~W}\end{array}$ & 85 & 10 & Less than 5 & $\begin{array}{l}\text { Less than } \\
3 \text { stories }\end{array}$ & LCZ 3 \\
\hline EQ-233 & Urban & $\begin{array}{l}7^{\circ} 06^{\prime} 48.14 " \mathrm{~N} \\
73^{\circ} 07^{\prime} 47.90^{\prime \prime} \mathrm{W}\end{array}$ & 85 & 10 & Less than 5 & $\begin{array}{l}\text { Between } \\
1 \text { and } 2 \\
\text { stories }\end{array}$ & LCZ 3 \\
\hline EQ-234 & Urban & $\begin{array}{l}7^{\circ} 07^{\prime} 02.41 " \mathrm{~N} \\
7^{\circ} 07^{\prime} 42.47^{\prime \prime} \mathrm{W}\end{array}$ & 50 & 40 & 10 & $\begin{array}{l}\text { Between } \\
4 \text { and } 5 \\
\text { stories }\end{array}$ & LCZ 2 \\
\hline EQ-235 & Urban & $\begin{array}{l}7^{\circ} 07^{\circ} 06.22^{\prime \prime} \mathrm{N} \\
7^{\circ} 07^{\prime} 29.02 \mathrm{~W}\end{array}$ & 89 & 10 & 1 & 5 stories & LCZ 2 \\
\hline
\end{tabular}

case, which would be the temperature that would be present if the city did not exist [11]. The other nodes were positioned to represent the most abundant local climate zones (LCZ) in the city, following the classification proposed by Stewart [4]. Those most common LCZ in the city are compact midrise (LCZ 2), compact lowrise (LCZ 3) and open midrise (LCZ 5). For the determination of the LCZ that best represents each node, the main surface properties (buildings, trees, impervious and permeable areas, and element height) within a radius of $100 \mathrm{~m}$ around the location of the node were analyzed. The assignment of a type of LCZ is not trivial, due to the lack of homogeneity in the elements of the city on a small scale. Each node reported a pair of temperature measurements (one for each thermometer) every minute. The nodes were installed at a height of approximately $5.5 \mathrm{~m}$, to avoid theft, vandalism, or traffic interference. Table 1 explains the LCZ assignation, showing the surface properties in the surroundings of every node, and indicates the position of each node and its category. Figure 2 shows the location of the nodes in a satellite image.

The data collection was carried out between 18 May 2018 and 21 August 2018. However, not all the sensors were active during the whole period, due to damage in some components and similar logistical motives. For this reason, data were distributed in three periods of time, which differ in the available nodes. Thereby, the correct comparability between the urban points and the reference site is guaranteed, ensuring the blocking of influential but

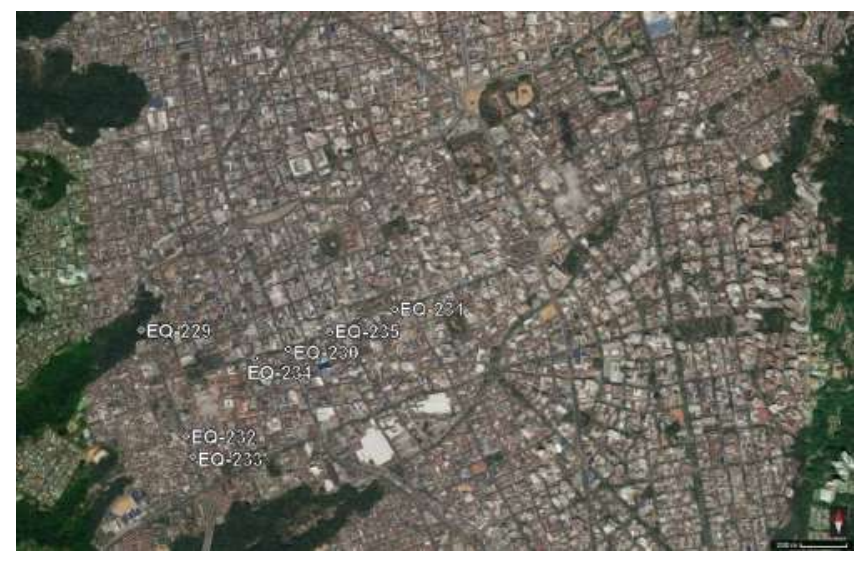

Figure 2 Spatial distribution of the measurement network in Bucaramanga. Location of each node is indicated by the white circles

uncontrollable factors, such as climate. Table 2 shows the three intervals of time in which the period of the study was divided, together with the active nodes in each interval.

Various data processing techniques were applied to the collected measurements. Detection and elimination of outliers was done using Tukey's test. For missing value imputation was used a replacement method, so known data were used to assign values to the missing data. For this purpose, a cubic spline was applied as interpolation replacement method. Finally, for noise 


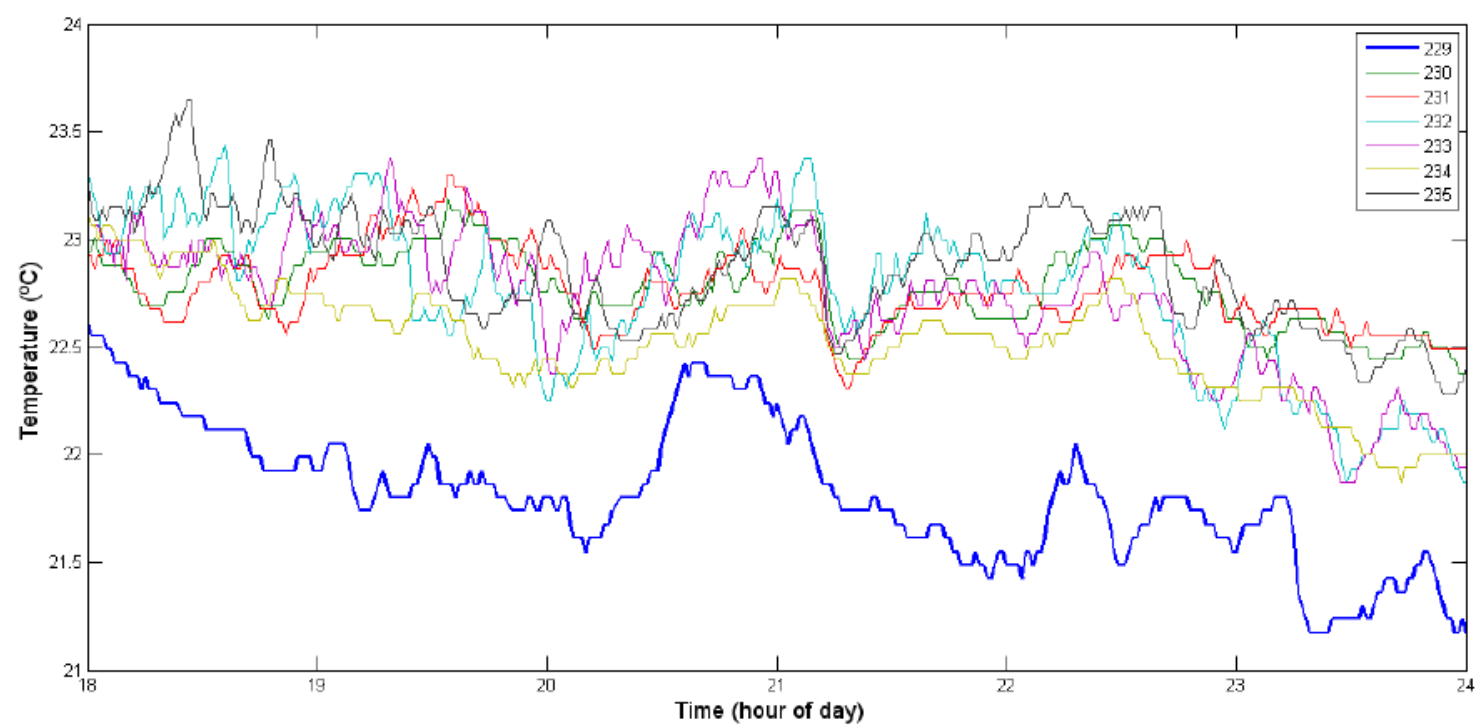

Figure 3 Temperature values collected by the seven measurement nodes between 1,800 h and 2,400 h on May 28, 2018. Blue line corresponds to reference node (EQ-229)

Table 2 Active nodes and dates of each of the three time periods in which the study interval was divided

\begin{tabular}{llcl}
\hline $\begin{array}{l}\text { Time } \\
\text { period }\end{array}$ & Dates & $\begin{array}{l}\text { Number of } \\
\text { days }\end{array}$ & $\begin{array}{l}\text { Active nodes } \\
\text { in the period }\end{array}$ \\
\hline P1 & $\begin{array}{l}2018-05-18 \\
\text { to }\end{array}$ & 11 & All \\
& $2018-05-28$ & & \\
\hline P2 & $\begin{array}{l}2018-05-29 \\
\text { to }\end{array}$ & 22 & $\begin{array}{l}\text { EQ-229, EQ-230, } \\
\text { and EQ-235 }\end{array}$ \\
& $2018-06-19$ & & \\
& $2018-06-29$ & & \\
& to & & \\
& $2018-06-29$ & & $E Q-229, E Q-230$, \\
P3 & and & 56 & EQ-233 and \\
& $\begin{array}{l}\text { 2018-07-07 } \\
\text { to }\end{array}$ & & \\
& $2018-08-21$ & & \\
\hline
\end{tabular}

filtering, two techniques were tested: moving average and Savitzky-Golay filter. These two noise filtering techniques were selected because of the relative simplicity of their implementation; additionally, Savitzky-Golay filter presents an excellent performance in terms of root-mean-square error (RMSE), compared with other noise reduction techniques [64-66].

\section{Results and discussion}

Data collection in the periods mentioned in Table 2 resulted in more than 620,000 temperature values, taking into account the seven measurement nodes. The frequency and simultaneity with which the data were acquired allowed blocking the effect of factors such as weather, background climate and time, avoiding biases in the results. In particular, the high temporal resolution of temperature measurements in the present study is one of its novel characteristics. However, capturing, managing and analyzing the large amount of data generated are challenging tasks, which are becoming more common in different applications due to advances in sensors, communications, processing and storage. These challenges are known as "big data" [63]. Figure 3 shows part of the raw temperature data measured on May 28 , 2018, which illustrates the typical behavior observed in the different nodes between 1,800 $\mathrm{h}$ and 2,400 $\mathrm{h}$. This 6-hour interval makes it possible to appreciate the resolution with which the temperature variations in the different nodes was measured.

The first step in data processing was outliers removal. For this end, Tukey's test was applied to two types of data sets: temperature values and battery charge level (which also was measured every minute). While there were not outliers in any of the temperature data sets from the nodes, there were some instances of outliers in battery charge level data, according to Tukey's test. Outliers identified were eliminated from all data sets. Figure 4 presents an example of outliers removal, corresponding to battery charge level of the EQ-233 node on June 1, 2018.

Subsequently, data completion was carried out using a cubic spline to assign values to the missing data, and this was done for the complete data sets. Thereby, a whole continuity of the temperature sets was achieved, and therefore a comprehensive comparability between data during each of the time periods was possible. Figure 

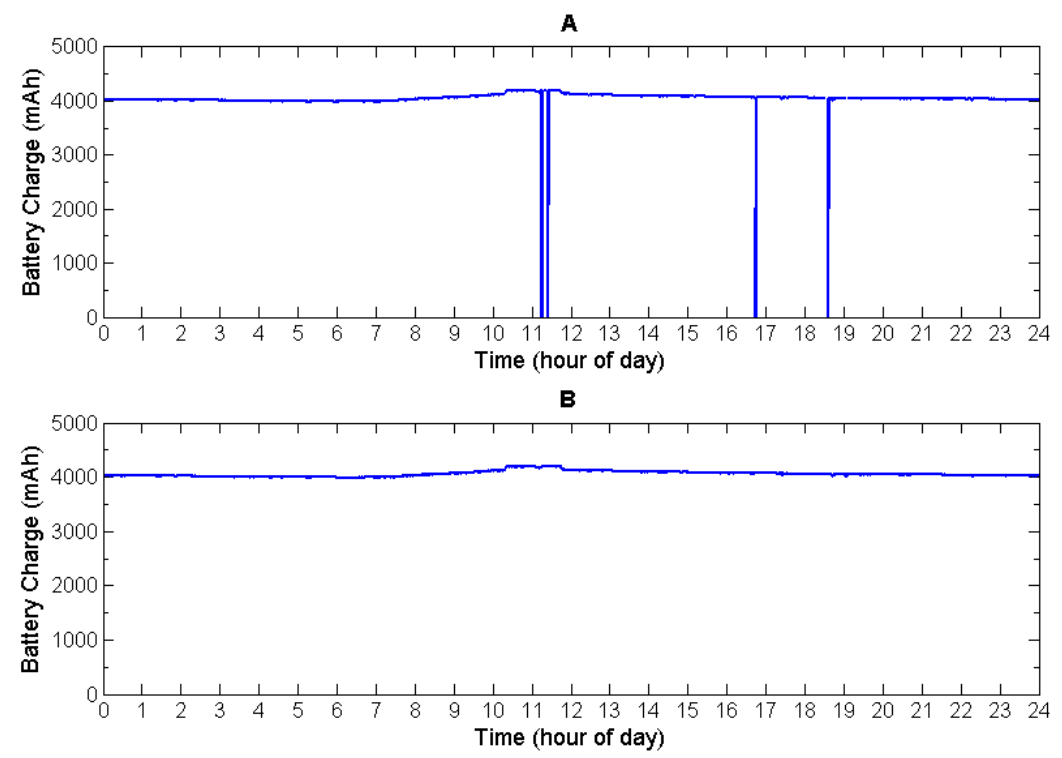

Figure 4 Example of elimination of outliers. (A) Battery charge raw data of the EQ-233 node on June 1, 2018. (B) Same data, after outliers deletion

5 shows an example of the result of the application of the cubic spline to impute the missing data.

The final step of data processing was noise reduction. Two noise filtering techniques were implemented and compared: moving average and Savitzky-Golay filter. It was considered that the latter presented better results for the temperature data sets, so it was chosen for the noise reduction. Figure 6 shows an example of the effect of the application of each of the two evaluated techniques of filtering.

The analysis of results began with a graphical analysis, comparing the temperatures measured by the nodes corresponding to each LCZ against the temperatures at the reference node, to identify general trends. This allows, on the one hand, to determine the UHI in Bucaramanga, and on the other, to evaluate whether the behavior of the $\mathrm{UHI}$ is a function of the LCZ. The location of the reference node tries to approximate the ideal reference temperature for a UHI study, which would be the pre-urban one; that is, the temperature that would occur if the city did not exist [67]. For this reason, the reference node was located on an edge of the city, which is covered by the natural flora of the sector (mainly trees; in the Supplementary Material, Figure S2 shows the appearance of the vegetation). In any case, the alternative type of point of reference, which consists in a rural location, was not viable for Bucaramanga. This is due to its geographical condition: as it is a plateau that is located in a mountain range, there are no nearby locations that coincide in altitude, vegetation and topology.
In general terms, it was found that there is a very defined $\mathrm{UHI}$ in the nighttime, while at daytime the city temperature can be slightly higher or lower than that of the reference site, depending on the type of LCZ of the location. LCZ 5 site (EQ-231) tends to show a lower temperature value during the day that the reference site. The trend of temperature in the LCZ 3 sites (EQ-232 and EQ-233) is fairly homogeneous, being slightly higher during daytime with respect to the reference node. Meanwhile, LCZ 2 sites (EQ-230, EQ-234 and EQ-235) exhibit a larger variability, with each node exceeding notably the reference temperature in some period of the day, but differing in the period of the day in which said behavior was evidenced (EQ-230 in the first hours of sunlight, EQ- 234 starting around $1000 \mathrm{~h}$, and EQ-235 after noon). Figure 7 shows the comparison of mean temperatures at each time of day, during period P1. In the other two periods of time (P2 and P3) there were similar trends; the respective graphs are included in the Supplementary Material (Figure S3 and S4).

Finally, mean daytime and nighttime air temperatures of every node in each of the three periods were calculated. Thereby, an average quantification of the trends evidenced in the graphical analysis of the data is achieved, and the result is more appropriate to quantify the real UHI intensity than other alternatives found in previous studies, such as reporting the maximum temperature difference between urban and reference sites. Additionally, it is possible to evaluate quantitatively if the LCZ type has effect on the magnitude of the UHI. The period between $0600 \mathrm{~h}$ and $1,800 \mathrm{~h}$ was defined as daytime, and the interval between 

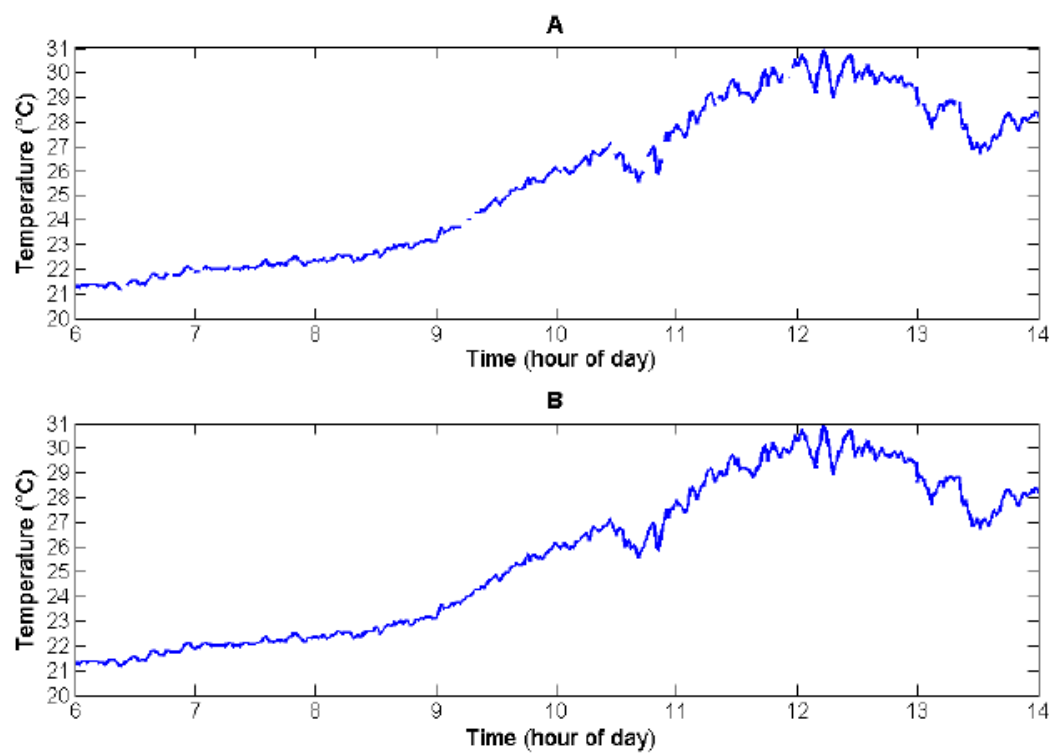

Figure 5 Example of missing data imputation using a cubic spline. Data shown corresponds to temperatures reported by EQ-233 node between $0000 \mathrm{~h}$ and 1,400 h on June 1, 2018

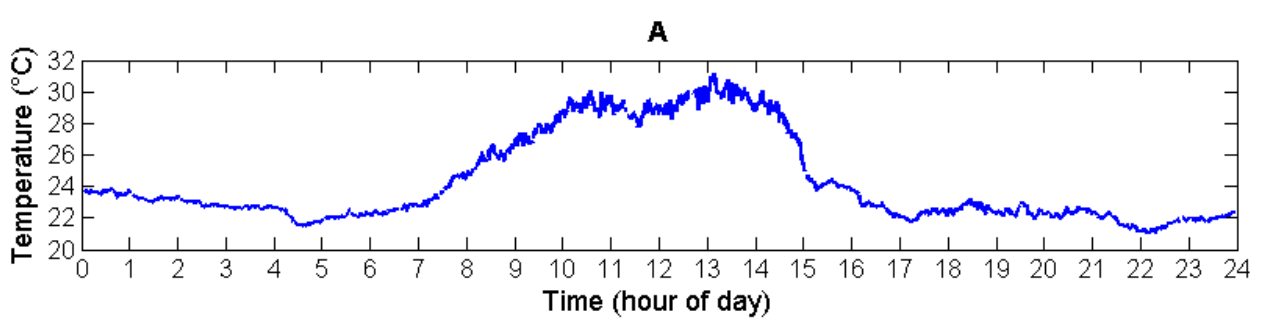

B

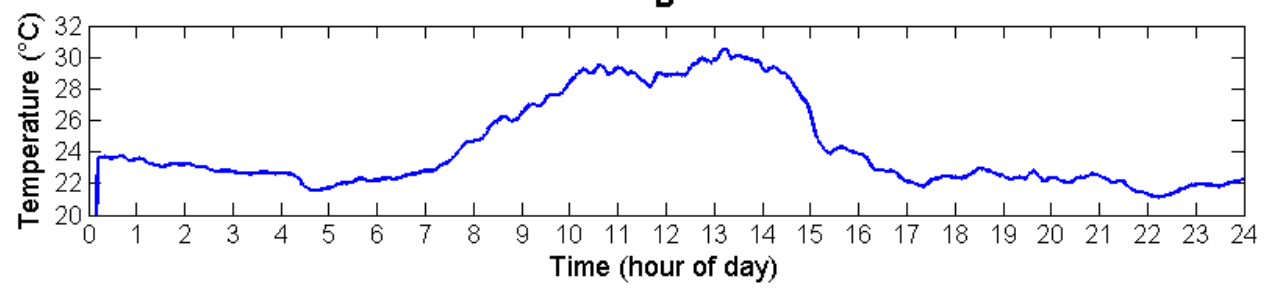

C

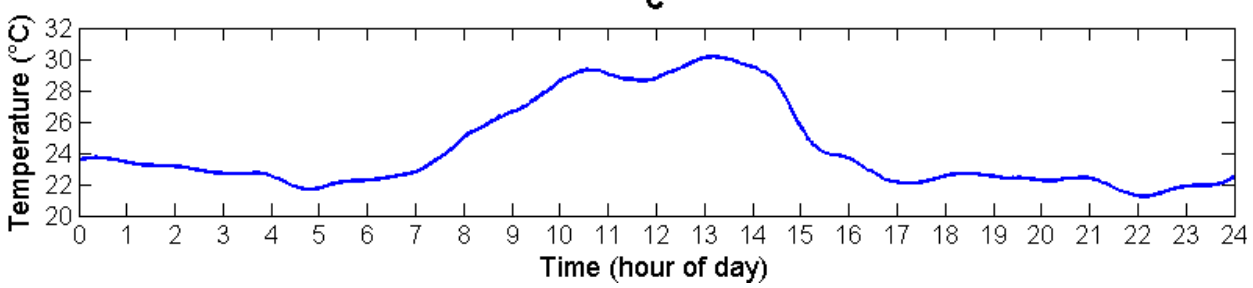

Figure 6 Comparison between noise reduction techniques, for temperature data collected by EQ-233 on June 1, 2018. (A) Raw data. (B) Data after application of moving average. (C) Data after application of Savitzky-Golay filter

$1,800 \mathrm{~h}$ and $0600 \mathrm{~h}$ as nighttime. Table 3 presents the results obtained.

Table 3 shows the difference that exists in the behavior of the UHI, between daytime and nighttime hours. In general, the magnitude of the $\mathrm{UHI}$ is greater at night than during the day, corroborating what had already been shown in Figure
7. The quantification of the mean temperatures shows that the nocturnal UHI has a fairly uniform magnitude, independently of the time period and the characteristics of the zone. The magnitude of the nocturnal UHI is, on average, $1.0^{\circ} \mathrm{C}$. In contrast, the magnitude of the daytime $\mathrm{UHI}$ is a function of both the LCZ of the site and the season. 
Table 3 Mean air temperatures measured by the different nodes in each period of the study, grouped by LCZ. $\triangle T$ : difference between mean temperature of the node and mean temperature of reference node. NA: not applicable. ND: no data

\begin{tabular}{|c|c|c|c|c|c|c|c|c|c|c|c|c|c|}
\hline \multirow{3}{*}{ LCZ } & \multirow{3}{*}{ Node } & \multicolumn{4}{|c|}{ P1 } & \multicolumn{4}{|c|}{ P2 } & \multicolumn{4}{|c|}{ P3 } \\
\hline & & \multicolumn{2}{|c|}{ Daytime } & \multicolumn{2}{|c|}{ Nighttime } & \multicolumn{2}{|c|}{ Daytime } & \multicolumn{2}{|c|}{ Nighttime } & \multicolumn{2}{|c|}{ Daytime } & \multicolumn{2}{|c|}{ Nighttime } \\
\hline & & $\begin{array}{c}\text { Mean } \\
{\left[{ }^{\circ} \mathrm{C}\right]}\end{array}$ & $\begin{array}{c}\Delta \mathrm{T} \\
{\left[{ }^{\circ} \mathrm{C}\right]}\end{array}$ & $\begin{array}{l}\text { Mean } \\
{\left[{ }^{\circ} \mathrm{C}\right]}\end{array}$ & $\begin{array}{l}\Delta \mathrm{T} \\
{\left[{ }^{\circ} \mathrm{C}\right]}\end{array}$ & $\begin{array}{l}\text { Mean } \\
{\left[{ }^{\circ} \mathrm{C}\right]}\end{array}$ & $\begin{array}{l}\Delta \mathrm{T} \\
{\left[{ }^{\circ} \mathrm{C}\right]}\end{array}$ & $\begin{array}{l}\text { Mean } \\
{\left[{ }^{\circ} \mathrm{C}\right]}\end{array}$ & $\begin{array}{l}\Delta \mathrm{T} \\
{\left[{ }^{\circ} \mathrm{C}\right]}\end{array}$ & $\begin{array}{l}\text { Mean } \\
{\left[{ }^{\circ} \mathrm{C}\right]}\end{array}$ & $\begin{array}{l}\Delta \mathrm{T} \\
{\left[{ }^{\circ} \mathrm{C}\right]}\end{array}$ & $\begin{array}{l}\text { Mean } \\
{\left[{ }^{\circ} \mathrm{C}\right]}\end{array}$ & $\begin{array}{l}\Delta \mathrm{T} \\
{\left[{ }^{\circ} \mathrm{C}\right]}\end{array}$ \\
\hline LCZ B & EQ-229 & 24.9 & NA & 21.5 & NA & 26.0 & NA & 21.8 & NA & 26.5 & NA & 21.7 & NA \\
\hline \multirow{3}{*}{ LCZ 2} & EQ-230 & 25.5 & 0.6 & 22.5 & 1.0 & 26.6 & 0.6 & 22.8 & 1.0 & 26.6 & 0.1 & 22.7 & 1.0 \\
\hline & EQ-234 & 25.6 & 0.7 & 22.2 & 0.7 & ND & ND & ND & ND & ND & ND & ND & ND \\
\hline & EQ-235 & 25.5 & 0.6 & 22.7 & 1.2 & 26.5 & 0.5 & 22.9 & 1.1 & 26.6 & 0.1 & 23.0 & 1.3 \\
\hline \multirow{2}{*}{ LCZ 3} & EQ-232 & 25.3 & 0.4 & 22.5 & 1.0 & 26.2 & 0.2 & 22.7 & 0.9 & ND & ND & ND & ND \\
\hline & EQ-233 & 25.2 & 0.3 & 22.4 & 0.9 & 26.1 & 0.1 & 22.7 & 0.9 & 26.1 & -0.4 & 22.6 & 0.9 \\
\hline LCZ 5 & EQ-231 & 24.6 & -0.3 & 22.4 & 0.9 & ND & ND & ND & ND & ND & ND & ND & ND \\
\hline
\end{tabular}

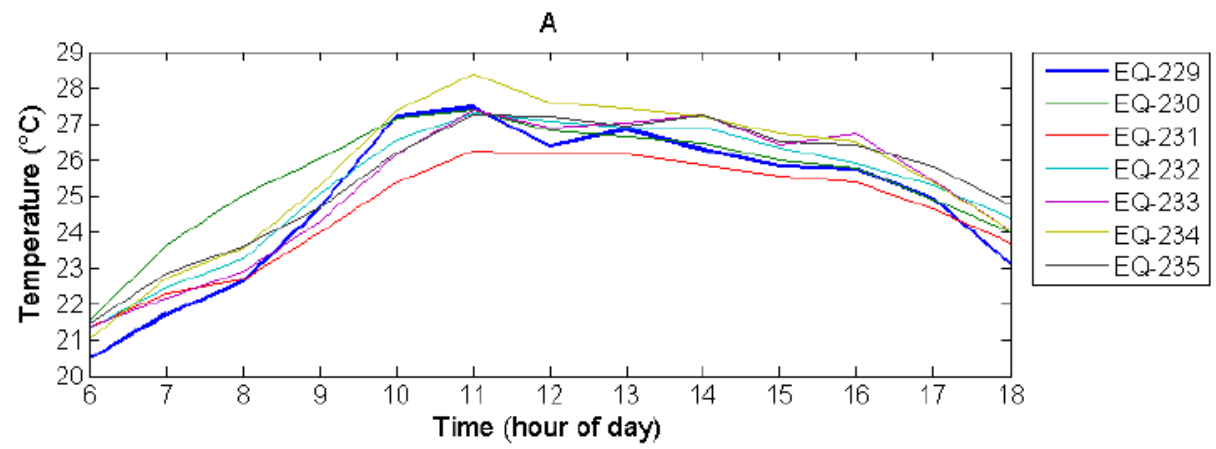

B

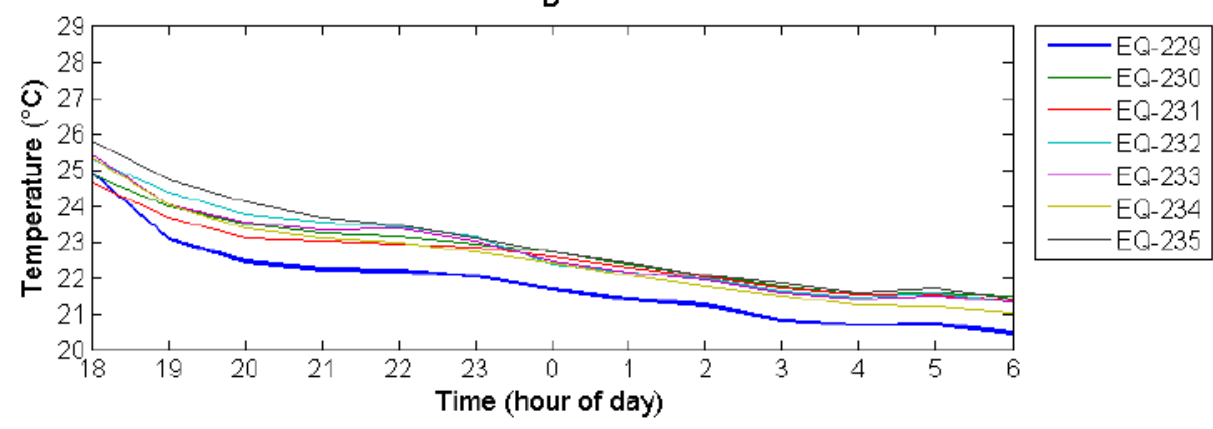

Figure 7 Mean temperature in the period P1, for each measurement node. Reference node is highlighted by using a thicker line. (A) Daytime temperatures (between $0600 \mathrm{~h}$ and 1,800 h). (B) Nighttime temperatures (between $1,800 \mathrm{~h}$ and $0600 \mathrm{~h}$ )

Regarding the relationship between daytime UHI and $L C Z$, the data collected show differentiated trends for each of the 3 types of LCZ covered in the study. The sites corresponding to LCZ 2 show diurnal UHI of greater magnitude, in all periods. A high homogeneity is observed in the mean daytime UHI value between these sites, being around $0.63{ }^{\circ} \mathrm{C}$ in the first period, decreasing slightly during the second, and falling to $0.1^{\circ} \mathrm{C}$ during the third. As for the sites represented by LCZ 3 , the diurnal temperature is consistently lower than in the places classified as LCZ 2, which leads to lower values of daytime UHI in all periods, even presenting an "urban cool island" (less temperature at the site than at the reference nodel during the last period, with a magnitude of $0.4^{\circ} \mathrm{C}$. This may be due to the particularities of the spatial location of the city, having a river canyon at one of its edges and surrounded by mountains in the opposite. Another possible cause are factors that were not measured in the present study, such as a difference in the average wind speed between the two seasons (rainy and dry). Finally, the site with LCZ 5 had the lowest daytime temperature of all, being $0.3^{\circ} \mathrm{C}$ lower than the reference node during the first period (damage in node's components made it impossible to have data in the other periods).

Another interesting effect that can be analyzed from the data is the impact of the season on the UHI magnitude. There is an evident increase in temperature as the periods advance, which is consistent with the transition from rainy season to dry season that coincides partially with 
the period 2. It is interesting to note that despite the increase in mean ambient temperature, nighttime UHI intensity remains approximately constant. On the other hand, diurnal UHI intensity tends to decrease as the mean ambient temperature increases, for all types of LCZ.

In general terms, the comparability of the different studies on $\mathrm{UHI}$ is very low, due to the significant methodological and conceptual differences between the various studies [4]. In addition, it is quite common to report the maximum UHI as a summary of the study [14], although this figure does not represent the average effect of the city's presence on temperature, but the UHI under certain specific conditions. A review of the UHI in tropical and subtropical cities suggests that the magnitude of those $\mathrm{UHI}$ is generally lower than that in cities of temperate regions [48]. That review deepens the analysis of 8 tropical and subtropical cities, in which the maximum value of UHI is between $1.0^{\circ} \mathrm{C}$ and $5.0^{\circ} \mathrm{C}$, although it is not difficult to find temperate cities with comparable maximum UHI (see for example [15, 30, 34, 37]). Taking into account the results of the present study, Bucaramanga is in the low range of values of the UHI, given that the maximum intensities did not reach values as extreme as those reported in other studies. In any case, Bucaramanga was an interesting case study for UHI because of its particular location, and because it is in a phase of vertical urban development due to the low availability of urban expansion land.

\section{Conclusions}

A real-time measurement network was deployed to investigate the possible existence of an $\mathrm{UHI}$ in Bucaramanga, Colombia. Temperature data were collected every minute for 89 days in multiple locations, and some techniques of data processing were applied: outlier removal, missing data imputation and noise filtering. The study demonstrates the existence of an $\mathrm{UHI}$ in Bucaramanga. This UHI manifests particularly at night, with a mean intensity of $1.0^{\circ} \mathrm{C}$. Therefore, although the impact of the existence of Bucaramanga on the local temperature is evident, the magnitude of the $\mathrm{UHI}$ is not particularly high. UHI intensity is very uniform at night across the city, being similar in the different studied places. On the other hand, during the day there is a high variability in the UHI intensity, depending on the local surface properties. Data show an important relation between the LCZ classification of the terrain and the daytime behavior of the UHI, although data in the present study are not sufficient to conclude in this regard. It is also possible to appreciate that the magnitude of the daytime UHI tends to decrease as the temperature increases, which happens in the dry season.

\section{Declaration of competing interest}

None declared under financial, profesional and personal competing interests.

\section{Acknowledgements}

Authors wish to thank Alumbrado Público de Bucaramanga, and especially to engineer Nicolás Cobos, for their invaluable help regarding the granting of the necessary permissions, and the positioning and disassembly of the measurement nodes.

\section{Supplementary material}

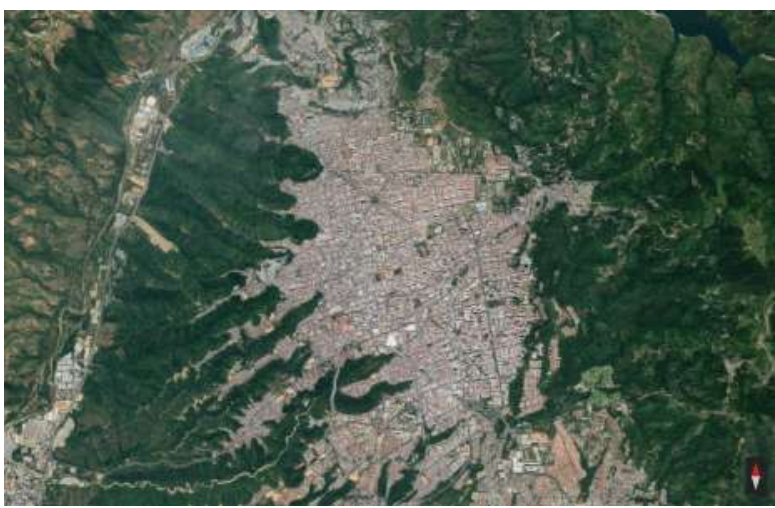

Figure S1 Satellite image of the city of Bucaramanga. The canyon of the Río de Oro can be seen to the left of the image, and to the right the eastern mountains

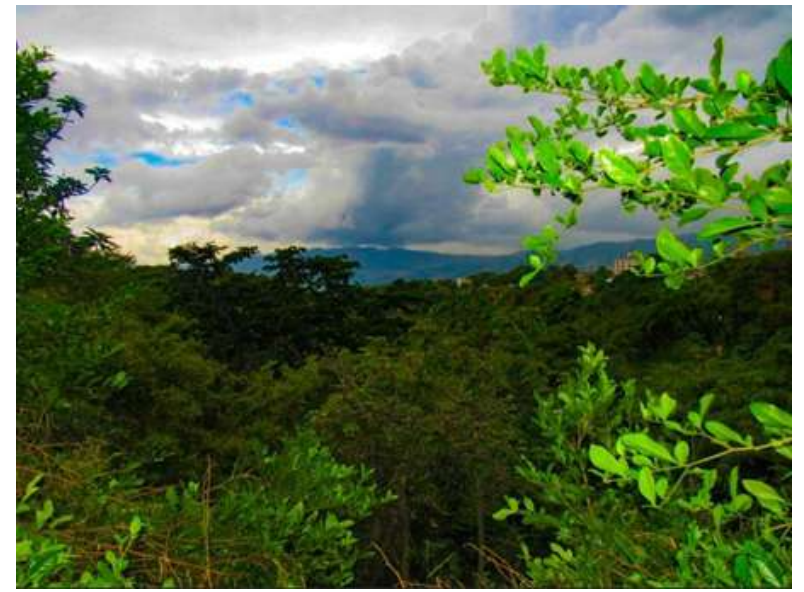

Figure S2 Natural vegetation of the site where Bucaramanga is located, currently existing in the surroundings of the reference node. The trees are located on a scarp, part of the Río de Oro canyon 
A
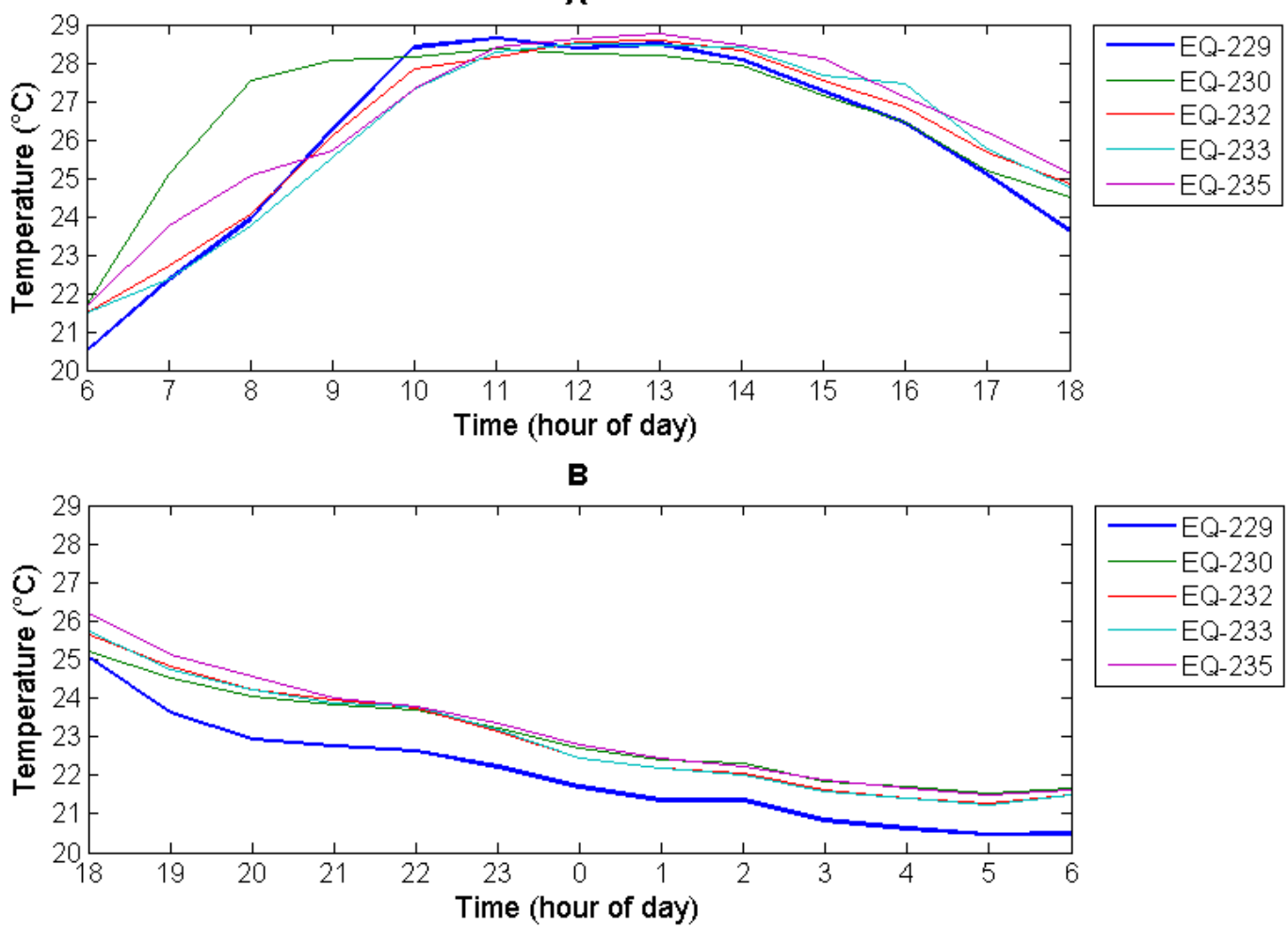

Figure S3 Comparison of mean temperature in different moments of the day, for the active nodes in period P2. (A) Daytime temperatures. (B) Nighttime temperatures
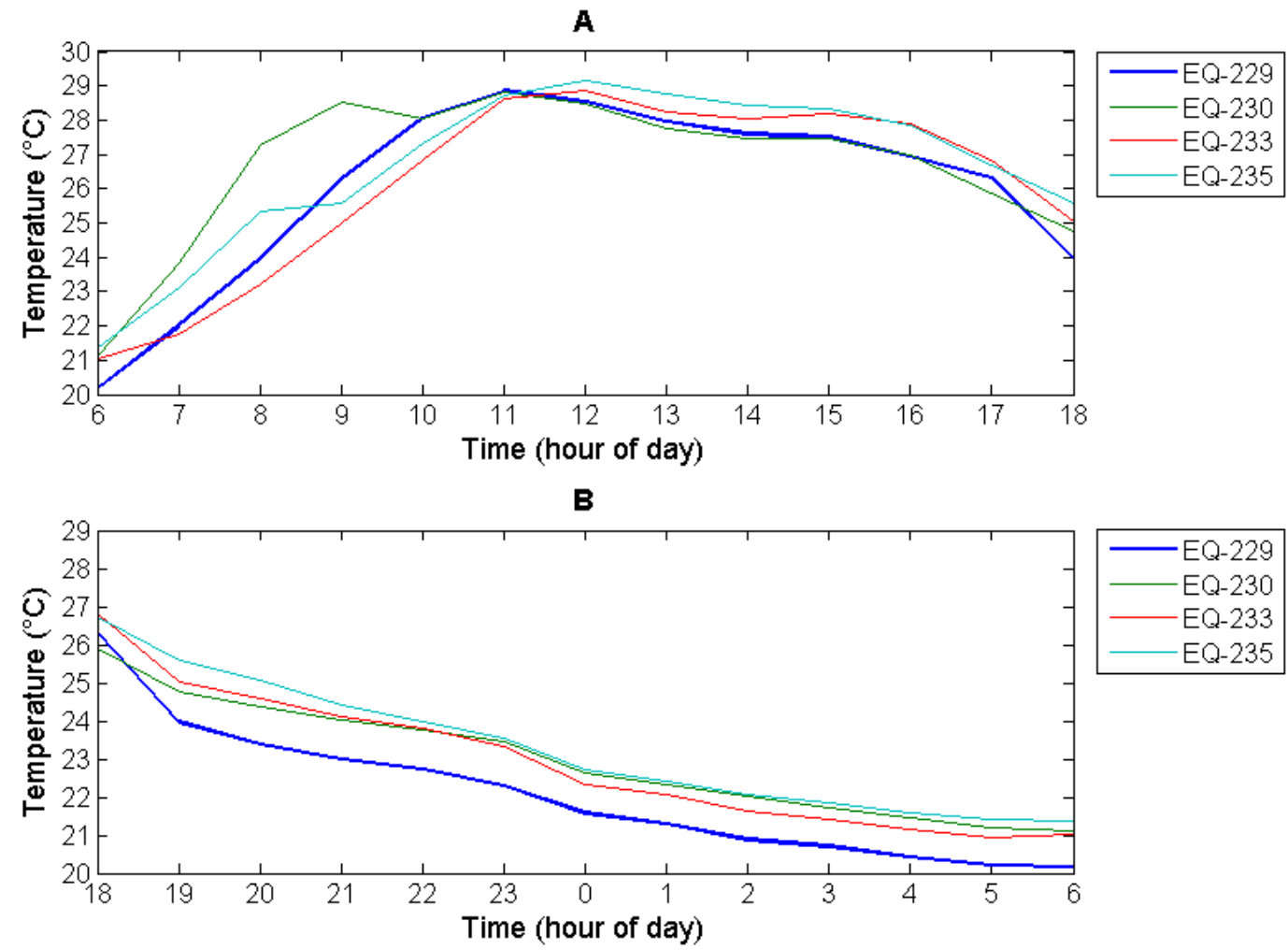

Figure S4 Mean temperatures in the period P3, for the active nodes. (A) Daytime temperatures. (B) Nighttime temperatures 


\section{References}

[1] A. J. Arnfield, "Two decades of urban climate research: a review of turbulence, exchanges of energy and water, and the urban heat island," International Journal of Climatology, vol. 23, January 102003. [Online]. Available: https://doi.org/10.1002/joc.859

[2] (2018) Urban population (Nov. 8, 2018. [Online]. Available: https: //bit.ly/2OKOdGV

[3] E. J. Gago, J. Roldan, R. Pacheco, and J. Ordóñez, "The city and urban heat islands: A review of strategies to mitigate adverse effects," Renewable and Sustainable Energy Reviews, vol. 25, September 2012. [Online]. Available: https://doi.org/10.1016/j.rser.2013.05.057

[4] I. D. Stewart, "Redefining the urban heat island," Ph. D. dissertation, The faculty of Graduate Studies(Geography), The University of British Columbia, Vancouver, Canada, 2011.

[5] T. R. Oke, "Classics in physical geography revisited: Sundborg, A. 1951: Climatological studies in Uppsala with special regard to the temperature conditions in the urban area," Progress in Physical Geography, vol. 19, no. 1, March 1 1995. [Online]. Available: https://doi.org/10.1177/030913339501900105

[6] N. Schwarz, U. Schlink, U. Franck, and K. Grossmann, "Relationship of land surface and air temperatures and its implications for quantifying urban heat island indicators-An application for the city of Leipzig (Germany)," Progress in Physical Geography, vol. 18, July 2012. [Online]. Available: https://doi.org/10.1016/j.ecolind.2012.01. 001

[7] A. A. Mohamed, J. Odindi, and 0. Mutanga, "Land surface temperature and emissivity estimation for Urban Heat Island assessment using medium- and low-resolution space-borne sensors: A review," Progress in Physical Geography, vol. 32, no. 4, 2017. [Online]. Available: https://doi.org/10.1080/10106049. 2016.1155657

[8] L. Sheng, X. Tang, H. You, Q. Gu, and H. Hu, "Comparison of the urban heat island intensity quantified by using air temperature and Landsat land surface temperature in Hangzhou, China," Ecological Indicators, vol. 72, January 2017. [Online]. Available: https://doi.org/10.1016/j.ecolind.2016.09.009

[9] J. M. Sobstyl, T. Emig, M. J. Abdolhosseini, F. J. Ulm, and R. Pellenq, "Role of city texture in urban heat islands at nighttime," Physical Review Letters, vol. 120, no. 10, March 2008. [Online]. Available: https://doi.org/10.1103/PhysRevLett.120.108701

[10] K. Klysik and K. Fortuniak, "Temporal and spatial characteristics of the urban heat island of Łódź, Poland," Atmospheric Environment, vol. 33, no. 24-25, October 1999. [Online]. Available: https: //doi.org/10.1016/S1352-2310(99)00131-4

[11] N. Magee, J. Curtis, and G. Wendler, "The Urban Heat Island Effect at Fairbanks, Alaska," Theoretical and Applied Climatology, vol. 64, no. 1-2, October 1999. [Online]. Available: https://doi.org/10.1007/ s007040050109

[12] S. Peng and et al, "Surface urban heat island across 419 global big cities," Environmental Science \& Technology, vol. 46, no. 2, 2012. [Online]. Available: https://doi.org/10.1021/es2030438

[13] R. A. Memon, D. Y. Leung, and C. Liu, "An investigation of urban heat island intensity (UHII) as an indicator of urban heating," Atmospheric Research, vol. 94, no. 3, November 2009. [Online]. Available: https://doi.org/10.1016/j.atmosres.2009.07.006

[14] R. Watkins, "The impact of the urban environment on the energy used for cooling buildings," Ph. D. dissertation, Department of Mechanical Engineering, Brunel University, Uxbridge, England, 2002.

[15] K. Fortuniak, K. Kłysik, and J. Wibig, “Urban-rural contrasts of meteorological parameters in Łódź," Theoretical and Applied Climatology, vol. 84, no. 1-3, February 2006. [Online]. Available: https://doi.org/10.1007/s00704-005-0147-y

[16] Q. Huang and Y. Lu, "Urban heat island research from 1991 to 2015: a bibliometric analysis," Theoretical and Applied Climatology, vol. 131, no. 3-4, February 2018. [Online]. Available: https: //doi.org/10.1007/s00704-016-2025-1

[17] J. Tan and et al, "The urban heat island and its impact on heat waves and human health in shanghai," International Journal of Biometeorology, vol. 54, no. 1, January 2010. [Online]. Available: https://doi.org/10.1007/s00484-009-0256-x

[18] M. Santamouris, C. Cartalis, A. Synnefa, and D. Kolokotsa, "On the impact of urban heat island and global warming on the power demand and electricity consumption of buildings-a review," Energy and Buildings, vol. 98, July 1 2015. [Online]. Available: https://doi.org/10.1016/j.enbuild.2014.09.052

[19] Y. Zhan, A. T. Murray, and B. L. Turner, “Optimizing green space locations to reduce daytime and nighttime urban heat island effects in Phoenix, Arizona," Landscape and Urban Planning, vol. 165, September 2017. [Online]. Available: https://doi.org/10.1016/j. landurbplan.2017.04.009

[20] C. Vancutsem, P. Ceccato, T. Dinku, and S. J. Connor, "Evaluation of MODIS land surface temperature data to estimate air temperature in different ecosystems over Africa," Remote Sensing of Environment, vol. 114, no. 2, February 15 2010. [Online]. Available: https: //doi.org/10.1016/j.rse.2009.10.002

[21] K. E. Runnalls and T. R. Oke, "Dynamics and controls of the near-surface heat island of Vancouver, British Columbia," Physical Geography, vol. 21, no. 4, 2000. [Online]. Available: https: //doi.org/10.1080/02723646.2000.10642711

[22] Z. Hu, B. Yu, Z. Chen, T. Li, and M. Liu, "Numerical investigation on the urban heat island in an entire city with an urban porous media model," Atmospheric Environment, vol. 47, February 2012. [Online]. Available: https://doi.org/10.1016/j.atmosenv.2011.09.064

[23] World Meteorological Organization. (2008) Guide to Meteorological Instrumentsand Methods of Observation WMO-No. 8. [World Meteorological Organization]. [Online]. Available: https://bit.ly/ $2 \mathrm{KWXMzB}$

[24] W. T. Chow and M. Roth, "Temporal dynamics of the urban heat island of Singapore," International Journal of Climatology, vol. 26, February 2012. [Online]. Available: https://doi.org/10.1002/joc.1364

[25] M. Kolokotroni and R. Giridharan, "Urban heat island intensity in London: An investigation of the impact of physical characteristics on changes in outdoor air temperature during summer," Solar Energy, vol. 82, no. 11, November 2008. [Online]. Available: https://doi.org/10.1016/j.solener.2008.05.004

[26] H. Park, "Features of the heat island in seoul and its surrounding cities," Atmospheric Environment, vol. 20, no. 10, 1986. [Online]. Available: https://doi.org/10.1016/0004-6981(86)90326-4

[27] T. S. Saitoh, T. Shimada, and H. Hoshi, "Modeling and simulation of the Tokyo urban heat island," Atmospheric Environment, vol. 30 , no. 20, October 1996. [Online]. Available: https://doi.org/10.1016/ 1352-2310(95)00489-0

[28] Y. Sakakibara and E. Matsui, "Relation between heat island intensity and city size indices / Urban canopy characteristics in settlements of Nagano basin, Japan," Geographical Review of Japan, vol. 78, no. 12, 2005. [Online]. Available: https://doi.org/10.4157/grj.78.812

[29] N. H. Wong and C. Yu, "Study of green areas and urban heat island in a tropical city," Habitat International, vol. 29, no. 3, September 2005. [Online]. Available: https://doi.org/10.1016/j.habitatint.2004.04.008

[30] T. Brandsma and D. Wolters, "Measurement and statistical modeling of the urban heat island of the city of Utrecht (the Netherlands)," Habitat International, vol. 29, June 2012. [Online]. Available: https: //doi.org/10.1175/JAMC-D-11-0206.1

[31] Y. Kim and J. Baik, "Maximum urban heat island intensity in Seoul," Journal of Applied Meteorology, vol. 41, June 2002. [Online]. Available: https://doi.org/10.1175/1520-0450(2002) 041<0651:MUHIII>2.0.CO;2

[32] R. Emmanuel and E. Johansson, "Influence of urban morphology and sea breeze on hot humid microclimate: the case of Colombo, Sri Lanka," Journal of Applied Meteorology, vol. 30, no. 3, April 2006. [Online]. Available: https://doi.org/10.3354/cr030189

[33] C. Yagüe, E. Zurita, and A. Martínez, "Statistical analysis of the Madrid urban heat island," Atmospheric Environment, vol. 25, no. 3, 1991. [Online]. Available: https://doi.org/10.1016/0957-1272(91) 90004-X

[34] T. W. Hawkin, A. J. Brazel, W. L. Stefanov, W. Bigler, and E. M. Saffell, "The role of rural variability in urban heat island determination 
for Phoenix, Arizona," Journal of Applied Meteorology, vol. 43, April 2004. [Online]. Available: https://doi.org/10.1175/1520-0450(2004) 043<0476:TRORVI>2.0.CO;2

[35] A. Velazquez, J. E. Gonzalez, and A. Winter, "Urban heat island effect analysis for San Juan, Puerto Rico," Atmospheric Environment, vol. 40, no. 9, March 2006. [Online]. Available: https://doi.org/10. 1016/j.atmosenv.2005.09.074

[36] P. D. Jones and D. H. Lister, "The urban heat island in Central London and urbanपrelated warming trends in Central London since 1900," Weather, vol. 64, no. 12, December 2009. [Online]. Available: https://doi.org/10.1002/wea.432

[37] L. Chapman, C. Bell, and S. Bell, "Can the crowdsourcing data paradigm take atmospheric science to a new level? A case study of the urban heat island of London quantified using Netatmo weather stations," International Journal of Climatology, vol. 37, no. 9, July 2017. [Online]. Available: https://doi.org/10.1002/joc. 4940

[38] C. I. Anderson, W. A. Gough, and T. Mohsin, "Characterization of the urban heat island at toronto: Revisiting the choice of rural sites using a measure of day-to-day variation," Urban Climate, vol. 25, September 2018. [Online]. Available: https: //doi.org/10.1016/j.uclim.2018.07.002

[39] R. L. Wilby, "Past and projected trends in London's urban heat island," Weather, vol. 58, no. 7, July 2003. [Online]. Available: https://doi.org/10.1256/wea.183.02

[40] P. A. Mirzaei and F. Haghighat, "Approaches to study Urban Heat Island - Abilities and limitations," Building and Environment, vol. 45, no. 10, October 2010. [Online]. Available: https://doi.org/10.1016/j. buildenv.2010.04.001

[41] D. Zhang, Y. Shou, and R. R. Dickerson, "Upstream urbanization exacerbates urban heat island effects," Geophysical Research Letters, vol. 36, no. 24, December 2009. [Online]. Available: https://doi.org/10.1029/2009GL041082

[42] I. D. Stewart, "A systematic review and scientific critique of methodology in modern urban heat island literature," International Journal of Climatology, vol. 31, no. 2, February 2011. [Online]. Available: https://doi.org/10.1002/joc.2141

[43] H. Akbari and et al, "Local climate change and urban heat island mitigation techniques - the state of the art," Journal of Civil Engineering and Management, vol. 22, no. 1, 2016. [Online]. Available: https://doi.org/10.3846/13923730.2015.1111934

[44] D. E. Parker, "Urban heat island effects on estimates of observed climate change," WIREs Climate Change, vol. 1, no. 1, January 2010. [Online]. Available: https://doi.org/10.1002/wcc.21

[45] I. Camilloni and V. Barros, "On the urban heat island effect dependence on temperature trends," Climatic Change, vol. 37, no. 4, December 1997. [Online]. Available: https://doi.org/10.1023/A: 1005341523032

[46] M. Haeger and B. Holmer, "Advection caused by the urban heat island circulation as a regulating factor on the nocturnal urban heat island," International Journal of Climatology, vol. 19, no. 9. July 1999. [Online]. Available: https://doi.org/10.1002/(SICI) 1097-0088(199907)19:9<975::AID- JOC399>3.0.CO;2-J

[47] U. Wienert and W. Kuttler, "The dependence of the urban heat island intensity on latitude - a statistical approach," Meteologische Zeitschrift, vol. 14, no. 5, October 10 2005. [Online]. Available: https://doi.org/10.1127/0941-2948/2005/0069

[48] M. Roth, "Review of urban climate research in (sub)tropical regions," International Journal of Climatology, vol. 27, 2007. [Online]. Available: https://doi.org/10.1002/joc.1591

[49] R. A. Memon, D. Y. Leung, and C. Liu, "A review on the generation, determination and mitigation of Urban Heat Island," Journal of Environmental Sciences, vol. 20, no. 1, 2005. [Online]. Available: https://doi.org/10.1016/S1001-0742(08)60019-4

[50] A. Tzavali, J. P. Paravantis, G. Mihalakakou, A. Fotiadi, and E. Stigka, "Urban heat island intensity: A literature review," Fresenius Environmental Bulletin, vol. 24, no. 12b, pp. 4537-4554, Jan. 2015.

[51] A. Aflaki and et al, "Urban heat island mitigation strategies: A state-of-the-art review on Kuala Lumpur, Singapore and Hong Kong," Cities, vol. 62, February 2017. [Online]. Available: https: //doi.org/10.1016/j.cities.2016.09.003

[52] Y. Shimoda, "Adaptation measures for climate change and the urban heat island in Japan's built environment," Building Research \& Information, vol. 31, no. 3-4, 2003. [Online]. Available: https: //doi.org/10.1080/0961321032000097647

[53] O. Aleksandrowicz, M. Vuckovic, K. Kiesel, and A. Mahdavi, “Current trends in urban heat island mitigation research: Observations based on a comprehensive research repository," Urban Climate, vol. 21, September 2017. [Online]. Available: https://doi.org/10. 1016/j.uclim.2017.04.002

[54] W. Zhou, G. Huang, and M. L. Cadenasso, "Does spatial configuration matter? understanding the effects of land cover pattern on land surface temperature in urban landscapes," Landscape and Urban Planning, vol. 102, no. 1, July 30 2011. [Online]. Available: https://doi.org/10.1016/j.landurbplan.2011.03.009

[55] L. Kleerekoper, M. Esch, and T. B. Salcedo, "How to make a city climate-proof, addressing the urban heat island effect," Resources, Conservation and Recycling, vol. 64, July 2012. [Online]. Available: https://doi.org/10.1016/j.resconrec.2011.06.004

[56] B. Zhou, D. Rybski, and J. P. Kropp, "The role of city size and urban form in the surface urban heat island," Scientific Reports, vol. 7, no. 1, July 6 2017. [Online]. Available: https: //doi.org/10.1038/s41598-017-04242-2

[57] Y. Wang, U. Berardi, and H. Akbari, "Comparing the effects of urban heat island mitigation strategies for Toronto, Canada," Energy and Buildings, vol. 114, February 15 2016. [Online]. Available: https://doi.org/10.1016/j.enbuild.2015.06.046

[58] P. A. Mirzaei, "Recent challenges in modeling of urban heat island," Sustainable Cities and Society, vol. 19, December 2015. [Online]. Available: https://doi.org/10.1016/j.scs.2015.04.001

[59] M. Santamouris, "Cooling the cities - A review of reflective and green roof mitigation technologies to fight heat island and improve comfort in urban environments," Solar Energy, vol. 103, May 2014. [Online]. Available: https://doi.org/10.1016/j.solener.2012.07.003

[60] H. E. Beck and et al, "Present and future Köppen-Geiger climate classification maps at 1-km resolution," Scientific Data, vol. 5, no. 180214, Octuber 30 2018. [Online]. Available: https://doi.org/10. 1038/sdata.2018.214

[61] Instituto de Hidrología, Meteorología y Estudios Ambientales (IDEAM. (2011) Promedios climatológicos 1981-2010. [Instituto de Hidrología, Meteorología y Estudios Ambientales (IDEAM]. Accessed Nov. 30, 2018. [Online]. Available: https://bit.ly/2XU5RKS

[62] Departamento Administrativo Nacional de Estadística (DANE). (2017) Población estimada de Bucaramanga, a partir del Censo 2005 extrapolando el comportamiento del periodo 1985 - 2005. [Departamento Administrativo Nacional de Estadística (DANE)]. Accessed Nov. 30, 2018. [Online]. Available: https://bit.ly/2DnQb9q

[63] S. Xu and et al, "Data cleaning in the process industries," Reviews in Chemical Engineering, vol. 31, no. 5, 2015. [Online]. Available: https://doi.org/10.1515/revce-2015-0022

[64] J. N. Hird and G. J. McDermid, "Noise reduction of NDVI time series: An empirical comparison of selected techniques," Remote Sensing of Environment, vol. 113, no. 1, January 15 2019. [Online]. Available: https://doi.org/10.1016/j.rse.2008.09.003

[65] G. Jifa and Z. Lingling, "Data, DIKW, Big Data and Data Science," Procedia Computer Science, vol. 31, 2014. [Online]. Available: https://doi.org/10.1016/j.procs.2014.05.332

[66] J. Chen and et al, "A simple method for reconstructing a high-quality NDVI time-series data set based on the Savitzky-Golay fiter," Remote Sensing of Environment, vol. 91, no. 3-4, June 30 2004. [Online]. Available: https://doi.org/10.1016/j.rse.2004.03.014

[67] W. P. Lowry, "Empirical estimation of the urban effects on climate: A problem analysis," Journal of Applied Meteorology, vol. 16, no. 2, January 1997. [Online]. Available: https://doi.org/10.1175/ 1520-0450(1977)016<0129:EEOUEO> 2.0.C0;2 